\title{
FILOLOGÍA FRANCESA
}





\title{
NUEVOS LECTORES EN EL SIGLO DE LAS LUCES A PARTIR DEL PRÓLOGO DE LA NOVELA FRANCESA DEL XVIII
}

\author{
Mercedes Navarro CAMEO \\ UNED. Madrid \\ meyesatelefonica.net
}

RESUMEN:

A partir del análisis del destinatario de los prólogos de novelas del Siglo de las Luces francés, se constata la aparición de un nuevo lector, explícitamente apelado e implícitamente configurado, que muestra una transformación y ampliación de las capas lectoras, con nuevos destinatarios de las obras, nombrados, reclamados, provocados, manipulados en ellas. Aparece un lector implícito que -dentro del espíritu didáctico y filosófico de este tiempo- se pretende educar. De manera muy explícita, los prólogos se dirigen ahora a la mujer, al público, al pueblo y al citoyen: nuevos lectores para nuevas condiciones y demandas de la escritura-lectura. La transformación de sus apelaciones se corresponde paralelamente con las literarias y sociales, en ese peculiar espíritu del Siglo de las Luces, que busca conciliar el individualismo con su proyección social.

Palabras Claves: Novela francesa del siglo XVIII; prólogos.

RESUME:

Les analyses du destinataire des préfaces romanesques du Siècle del Lumières montrent les étapes d'apparition de nouveaux modèles de lecteurs, appelés d'une façon explicite par les auteurs, et implicitement configurés. On constate ainsi une transformation et un élargissement des sujets lecteurs, ce qui comporte l'établissement de nouveaux destinataires pour les œuvres, qui se voient réclamés, désignés, provoqués et même manipulés par ces œuvres elles-mêmes. Ce lecteur implicite qu'on en- 
tend élever -dans le cadre de l'esprit philosophique et didactique de l'époque- devient de plus en plus important. Si bien que, de façon très explicite, les préfaces vont désormais s'adresser en particulier à la femme, au public, au peuple et au citoyen: des nouveaux lecteurs pour de nouvelles conditions et exigences de l'écriture/lecture. Or, la transformation de ces appellations se trouve en parallèle avec celles qui se produisent sur les plans littéraire et social, dans cet esprit si particulier au Siècle des Lumières qui entend concilier l'individualisme et son épanouissement social.

Most-CLEF: Roman français du XVIIIème siècle; préfaces.

Las transformaciones que se operan en el Siglo de las Luces -tanto en el modo como en la variedad de las lecturas, en los distintos y nuevos lectores que acceden a su práctica tanto en la capital como también en las ciudades de provincias y en los pueblos, tanto entre los hommes de lettres o savants como en los menos cultos, y tanto en la aristocracia como en la alta burguesía o las clases más bajas, entre comerciantes, artesanos, asalariados y servidumbre- son esenciales para la comprensión de las formas literarias del siglo XVIII. Entre las nuevas categorías que, de modo más significativo, acceden al consumo del libro, figuran los campesinos enriquecidos, los artesanos acomodados y sobre todo la mujer, la gran lectora de novelas. Si resulta obvio que hablar del gusto del público en general no determina el lector real en concreto, sabemos que, en esta época, París es el centro cultural de Europa, que todos los autores literarios buscan consagrarse en París y que allí se concentran los principales elementos que determinan la literatura, en ciertos lugares privilegiados: en la Academia, los Salones, los clubs, los cafés, las logias masónicas - que, a imitación de Inglaterra, se fundan en muchas ciudades de provincia en el siglo XVIII y se convierten en lugares de intercambio cultural y de textos, centros de debate y lectura, etc. Lógicamente, el público que frecuenta estos lugares tiene una sólida cultura: la que recibe en los colegios, especialmente y hasta 1764 en los Jesuitas, donde se imparte una enseñanza sobre todo literaria, y donde, en un principio, se privilegiaba a la literatura latina para, rápidamente presentar a la francesa como modelo, con Boileau y Racine a su cabeza.

Su público, el público que frecuenta estos lugares no es, en consecuencia, difícil de establecer. Pero, según R. Darnton ${ }^{1}$, los escritores, académicos, obispos, etc., ya no son los lectores representativos de este siglo que nos ocupa. Y tampoco considera fácil determinar qué es lo que realmente leen los franceses, ya que el hecho de que existan unas grandes bibliotecas no significa que éstas sean las más frecuentadas. Por lo general, al público popular comienzan a no atraerle demasiado las colecciones que durante tanto tiempo le han sido destinadas, como la conocida Bibliothèque bleue de Troyes, ${ }^{2}$ orientada hacia la difusión de textos antiguos, las adaptaciones de novelas de la Edad Media, las vidas de santos, los al-

\footnotetext{
${ }^{1}$ Véase las siguientes obras de este autor: Darnton, Robert, El coloquio de los lectores, Fondo de Cultura Económica, México, 2003; Bohème littéraire et Révolution. Le monde dans les livres au XVIII siècle, Gallimard, Paris, 1983; Édition et sédition. L'Univers de la littérature clandestine au XVIIIe siècle, Gallimard, Paris, 1991; The Corpus of Clandestine Literature in France, 1769-1789, Ed. Norton, New-York \& London, 1995.

${ }^{2}$ Se trata de una colección cuya denominación alude a los títulos editados en Troyes, entre el siglo XVII y el siglo XIX, en la Biblioteca-Librería de Nicolas Oudot. La impresión era de mala calidad y la cubierta estaba hecha con papel azul. Se la considera una literatura destinada a las clases humildes y era vendida por buhoneros ambulantes. Para algunos historiadores, fue la principal fuente de la cultura de masas, mientras que otros, como C.
} 
manaques o las obras prácticas, que había de simbolizar el modelo de libro económico de la época, con un gran volumen de impresión y vendido por los buhoneros, de gran difusión y fácilmente reconocible por su encuadernación azul, y desarrollado en Troyes desde comienzos del siglo XVII - en efecto, su denominación alude a su aspecto físico y a su origen. La sociología de la literatura ha probado que este público popular se irá orientando hacia otro tipo de lecturas.

Por otro lado, la burguesía accede con más facilidad a las novedades, y entre sus integrantes debemos situar a comerciantes o a personas de los ámbitos judiciales, a rentistas, médicos, curas, oficiales de la administración real o fiscal, etc. Aunque ello no quiera decir que el gusto literario deje de detentarlo la aristocracia, y que ésta deje de influir en la opinión pública mediante los círculos de reunión y conversación. Sabemos, por ejemplo, que su influencia es real entre los académicos. Con respecto a los escritores, es sabido que la aristocracia los reclama, pero que la atracción también se produce en sentido contrario. De este modo, la nobleza acoge abiertamente las nuevas ideas, como todo aquello que se presenta como original, nuevo, diferente y atrevido, aunque solo sea por mera reacción contra el conformismo burgués y la rutina popular. En estos ambientes, a menudo se predica un espíritu libertino que privilegia el desarrollo de un espíritu crítico, en ocasiones hostil al absolutismo monárquico. Es, pues, un hecho que ciertos gustos aristocráticos influyen enormemente en la literatura del siglo XVIII, aunque deba señalarse que más en el teatro y en la poesía que en la novela, así como en las formas dialogales - no cabe olvidar que recuerdan la práctica de la conversación en sus niveles más nobles y brillantes, y que los Salones, con su esprit, siguen constituyendo un espacio femenino en los que encuentran su mejor espacio expresivo asuntos tan diversos como puedan serlo la elegancia, el erotismo, los paseos campestres y el gusto por los viajes, o la guerra, la historia o los asuntos de la Corte.

De manera que, con respecto al público lector de novelas, puede decirse que, en su mayoría, pertenece a la burguesía parlamentaria y a profesiones liberales, que se compone de clases acomodadas y de pueblo instruido. Ciertamente, la cultura del público lector del siglo XVIII es compleja y depende además de las diferencias sociales y de sexo. Se suele afirmar que el público femenino es el que mayoritariamente se interesa por la novela pero, a diferencia de lo que ocurre en la actualidad, no se dispone de encuestas irrefutables ni de datos contrastados que lo demuestren, al margen de deducciones al alcance de cualquiera, de las propias referencias de los personajes femeninos en las novelas o de la iconografía de la época, entre otros elementos. Por ello, parece más prudente, en lugar de hacer hipótesis sociológicas, ceñirnos a los textos que permiten vislumbrar un destinatario ${ }^{3}$ explícito o implícito y, en cualquiera de

Ginzburg insisten en la ignorancia de los lectores a la hora de comprender el texto, en comparación con la importancia de la cultura oral, hasta el siglo XVIII. Los analfabetos la usaban para apreciar los grabados que no siempre concordaban con el texto, aunque podían oírlo en sesiones de lectura colectiva, y sus títulos solían incluir almanaques, predicciones astrológicas, consejos de todo tipo, poesías, romances, etc. Se ha estudiado su uso por Perrault como fuente para algunas de sus composiciones. En el resto de países europeos habían de darse fenómenos similares: los Chapbook ingleses, los Volksbuch alemanes o la literatura de cordel en España, que se mantendría hasta comienzos del siglo XX. Véase, a su respecto, el estudio ya canónico de Geneviève Bollème, $L a B i$ bliothèque bleue, Ed. Julliard, París, colección Archives, 1971.

${ }^{3}$ Existen trabajos precedentes muy interesantes en esta misma dirección, que, situados en distintos cronotopos, se han interesado por el destinatario de las obras a partir de sus prólogos. Referiré por su interés los dos 
los dos casos, puedo adelantar como un hecho innegable la aparición de un nuevo lector que, por un lado, descubren los autores, y al que, por otro, demandan y pretenden crear, educar y configurar.

Hechas estas puntualizaciones, creo posible hablar, tal y como lo hace la moderna crítica, de la aparición y configuración de un nuevo lector -y ya no sólo en el sentido expuesto anteriormente- con el que la nueva concepción de la lectura condiciona la aparición de nuevos autores al tiempo que se amplían las capas de lectores. No me refiero ahora a la distinta actitud de ambos con respecto a la función social de la escritura y la lectura respectivamente, sino a la aparición explícita y real de nuevos destinatarios de las obras, nombrados, reclamados, aclamados, provocados y configurados en ellas. Se trata de un nuevo lector al que -dentro del espíritu didáctico que caracteriza al escritor de este tiempo- se pretende educar. Y, en este sentido, no es difícil constatar, de manera muy explícita en nuestros prólogos, la aparición de nuevas categorías de lectores: entre ellos, especialmente, la mujer, el público, el pueblo y el citoyen.

Con respecto a la mujer, ya he indicado que la lectura le resulta especialmente valiosa, ya que es el medio más cercano del que dispone para acceder a la cultura en su época. Sobre todo, si tenemos en cuenta lo distintas que resultan la educación femenina y la masculina. Cuando M. Vovelle se refiere a la educación de la mujer de esta época, considera que ésta se concibe en función de su cometido social y doméstico. No es ocioso al respecto recordar las afirmaciones de Rousseau en su Émile, en las que subraya que toda la educación de las mujeres debía guardar relación con los hombres, ya que su fin radicaba en formar esposas eficaces y agradables, madres capaces de educar correctamente a sus hijos. Es un hecho que la educación de la mujer ${ }^{4}$ se encontraba sometida a su futura función social y doméstica, por lo que nada tiene de extraño que las mujeres más preparadas reclamaran un cambio real en la orientación de la educación y una igualdad en el saber de ambos sexos. Son elementos fuera de toda duda ya en los Salones del siglo XVII. Pues bien, refiriéndose al XVIII, M. Vovelle señalará:

Los hombres de la Ilustración intercambian de manera regular con las mujeres ideas y conceptos, pero dudan de las posibilidades intelectuales de la Mujer. Mientras la Ilustración declara la guerra a los prejuicios de la razón, a los filósofos no les pasa por la cabeza abandonarlos para pensar lo femenino. $Y$, mientras sitúan en el centro de su discurso la noción universal y el principio de igualdad, fundados en el derecho natural, defienden la idea de una naturaleza femenina aparte e inferior. ${ }^{5}$

siguientes: A. Porqueras Mayo, El prólogo como género literario (su estudio en el Siglo de Oro Español), Consejo Superior de Investigaciones Científicas, Madrid, 1957, o el artículo de A. Yllera (1990): «"Amigo lector"/ "vulgo tirano": La interacción autor /lector en el prólogo de obras de ficción», Investigaciones semióticas III, vol. 2., UNED, Madrid, pp. 523-533, referido a los prólogos autoriales de obras de ficción del cronotopo XVI-XVII español y francés, principalmente.

${ }^{4}$ La cuestión de la educación femenina hace correr auténticos ríos de tinta, y ya desde el siglo anterior abundan los alegatos en su favor (Mlle de Scudéry, Mme de Sévigné, Fénelon, etc.) En la época que nos ocupa, Mme de Graffigny, Mme Riccoboni, etc., utilizan la novela para denunciar los defectos de la educación femenina y proponer un sistema más democrático y satisfactorio (Lettres d'une Péruvienne, Histoire d'Ernestine, respectivamente).

${ }^{5}$ Vovelle, Michel, El hombre de la Ilustración, Alianza Editorial, Madrid, 1995, p. 402. 
Así es como la mujer pretende no quedar al margen de los progresos de este siglo rico en innovaciones intelectuales, y toma conciencia de las dificultades de su participación activa en una cultura que no le está destinada, por lo que su único recurso es mantenerse al corriente de los debates de su tiempo, escuchando y leyendo y, en ocasiones, provocándolo o escribiendo ella misma. De este modo, poco a poco, la mujer se convertirá en destinataria, autora y, a menudo, en personaje principal de la novela. Como personaje, resulta atractivo por su sensibilidad y complicaciones psicológicas, y el hecho de que la veamos escribir novelas de modo creciente se debe en buena medida a que, ya que no se requiere un reglamento preestablecido ni una preparación especial de poesía o retórica para llevarlo a cabo, se encuentra en condiciones de hacerlo. Son estos mismos elementos los que explican que acabe resultando una gran destinataria de las mismas. Pero también son bien conocidas las dificultades que encontrará al respecto, desde el rechazo masculino hacia esta usurpación de un espacio que buena parte de los autores consideran propio hasta los tópicos que le son destinados - y que constituyen en sí mismos otros tantos insultos a la inteligencia, derivados de un paternalismo propio de un concepto patrimonialista de su persona y su función, no sólo en un plano personal sino también institucional. Así, puede verse que la mujer, por ejemplo, se convertirá en una de las principales víctimas de los peligros de la lectura, bien por querer emular al hombre a través de la erudición, bien, naturalmente, por abandonarse a los sueños o a la inevitable lascivia... M. Vovelle lo expresa de un modo contundente:

mientras la lectura masculina es señal de actividad intelectual, a la mujer que lee se la considera fácilmente como una pedante orgullosa o una perezosa. La razón es que en ambos casos transgrede su función tradicional, al querer acceder a un saber masculino y robar el tiempo que debería consagrar a la dirección de la casa, al marido y a los hijos y crear entre ella y el libro un espacio íntimo del que está excluido el hombre. La lectura femenina es peligrosa. Si sobre su mesa reposan libros serios, es que la lectora quiere hacerse erudita, quiere ocupar el lugar del hombre. Si sostiene en la mano o sobre sus rodillas una novela, la lectora va a entregarse a los sueños, al abandono y a la lascivia . ${ }^{6}$

En cualquier caso, a pesar del recelo existente frente a la lectura femenina, a pesar de las prevenciones al respecto que, por ejemplo, aparecen en nuestros prólogos, la mujer del Siglo de las Luces se desvela como una gran lectora y, de manera natural, acabará convirtiéndose en un nuevo e importante destinatario de las obras. Si el discurso de ciertos autores resulta tan retrógrado como el de Rousseau en su Émile, cuando dice: Si la femme est faite pour plaire et pour être subjuguée, elle doit se rendre agréable à l'homme au lieu de le provoquer... ${ }^{7}$, también existen excepciones como en el caso de Laclos cuando, dirigiéndose a la mujer del modo más explícito y perlocutivo, exclama:

Oh! femmes, approchez et venez m'entendre (...) venez apprendre comment, nées compagnes de l'homme, vous êtes devenues leur esclave; comment, tombées dans cet état abject,

\footnotetext{
${ }^{6}$ Ibid., p. 416.

${ }^{7}$ Rousseau, J-J, Émile ou de l'Éducation, «Sophie ou la femme» (Livre IV), Garnier Flammarion, Paris, 1966, p. 466.
} 
vous êtes parvenues à vous plaire, à le regarder comme votre état naturel (...) Apprenez qu'on ne sort de l'esclavage que par une grande révolution... elle dépend de vous. ${ }^{8}$

De esa revolución forma parte el dominio del espacio de la escritura y, ciertamente, la primera de sus etapas es la lectura. No en vano se afirma a menudo que toda buena lectura necesita una capacidad de concentración similar, al objeto de no dejar escapar ni uno de los posibles matices del autor, a la de la escritura. La mujer es un nuevo lector al que muchos consideran que es preciso guiar y educar, proteger ante los peligros de la lectura o, por el contrario, invitarla a ellos, llevarla a la acción a través de la lectura, mediante un discurso tan perlocutivo como el indicado, en el que el deíctico, el imperativo, o el significado de las formas verbales «venid», «aprended» $\mathrm{y}$ «de vosotras depende», conforman un discurso de la acción en el que decir es hacer, en el que decir es provocar, concienciar y animar al acto, en este caso concreto al acto revolucionario. En cualquier caso, lo menos que puede decirse es que se trata de un discurso que pretende causar efecto en la lectora, en femenino, a la que se dirige, sin olvidar que coexiste una tendencia cierta, por parte de ciertos autores y por parte de la crítica en general, a presentar la lectura de novelas en concreto como una grave amenaza contra la salud moral del lector, y muy especialmente de las lectoras, en las que, dicen, propicia el ocio, la inmoralidad o la lujuria. Pero, paradójicamente, nuestros prólogos demuestran que los autores les siguen dedicando sus obras en mayor porcentaje que a otros destinatarios, y, dado que una de las funciones principales del prólogo es llevar a cabo la elección de un público, en los de la novela francesa del XVIII la mujer es su destinatario más importante. Un ejemplo paradigmático figura en las declaraciones de Marivaux en su prólogo a Les aventures de *** ou les effets surprenants de la sympathie (1713). ¿A quién se dirige su avis au lecteur?:

C'est à ces honnêtes spirituels, qui par une supériorité de goût et de génie ont le secret d'en savoir autant que ces savants jurés, sans être pédants comme eux; c'est aux dames, juges équitables des mouvements d'une passion qu'elles causent, et qu'elles ressentent elles-mêmes plus délicatement que nous, que j'adresse cette Préface. ${ }^{9}$

Más adelante, el autor deja bien clara otra de las razones que fundamentan la elección del público femenino para su novela: Quand un roman attendrit les dames, en vain on crie qu'il ne vaut rien; le coeur est gagné (...) Y es que la mujer tiene una predisposición natural hacia la novela, ya como lectora, ya como escritora: veamos como lo expresa el prólogo de la obra anónima Valentine (1786)

L'orgueil mal entendu, les erreurs de l'amour-propre, et une infinité d'actions qui deviennent criminels par les artifices et la fausseté dont on les accompagnait, ont disparu avec la galanterie; mais ce qui sera aussi éternel que ce sexe lui-même, c'est son goût pour les livres et les récits qui, animant le feu des passions, font naître cette espèce d'enchantement dont les femmes sont remplies et qu'elles se plaisent à répandre sur tout

${ }^{8}$ Laclos, Des femmes et de leur éducation, in Laclos. CEuvres complètes, Gallimard, coll. «Bibliothèque de la Pléiade», Paris, 1979, pp. 390-391.

${ }^{9}$ Marivaux, Pierre Carlet de Chamblain de, Les aventures de *** ou les effets surprenants de la sympathie, 1713, in Marivaux Romans. Gallimard, coll. «Bibliothèque de la Pléiade», Paris, 1972. 
ce qui les environne; elles sont souvent dupes elles-mêmes des illusions qu'elles veulent faire naître, et toutes les fois que celui qui attend d'elles le mensonge du bonheur les surprend dans cette douce rêverie qui suit ordinairement la lectures des seuls libres qu'elles puissent aimer... La disposition de leur âme prépare sa victoire ; elle lui coûte peu d'efforts. Comment n'aimeraient-elles pas les romans, et ne réussiraient-elles pas à en faire? C'est une nécessité pour elles que d'aimer. Après avoir épuisé ce sentiment pour tout ce qui environnait leur jeunesse, souvent, dans la maturité de l'âge, leur imagination se crée des attachements parmi les êtres fantastiques. Ce sont elles qui, dans tous les pays, assurent, par cette disposition de l'esprit et du cour,... (...) Cette disposition des organes et des sensation dans les femmes, les rend très propres aux ouvrages d'esprit, où l'imagination et la magie des passions jouent le rôle principal; et si plus que jamais elles se mêlent d'écrire, on peut dire qu'elles travaillent plus que jamais à se rendre dignes d'être lues ; (...) en un mot, les femmes de ce siècle sont au dessus de ce que l'on peut désirer d'elles, car elles ont la tradition vivante du plaisir et du bonheur de tous les âges précédents, et chaque jour elles ajoutent à la félicité commune par les grâces de leur esprit et la douce aisance qu'elles donnent à nos mœurs ${ }^{10}$.

Otro ejemplo bien representativo de este fenómeno viene dado por el prólogo de otra obra anónima dirigida al bello sexo:

Au beau sexe :

Mes Dames, (...) je serai plus que content si vous voulez bien lire ce recueil d'histoires choisies...(...) où vous trouverez de quoi vous divertir, et de quoi vous instruire. Que ce mot, Mes Dames, ne vous fasse pas de peine, (...) C'est en effet, auprès de vous, Mes Dames que l'on apprend l'art de bien vivre (...) Persuadées de mon profond respect pour vous, Mes Dames, soyez assurées que je ne vous rapporterai aucune aventure qui ne soit absolument véritable (...) le mensonge ne cadrerait pas avec l'estime que j'ai pour le beau sexe. (...) Mes Dames, votre très humble, très obéissant et très dévoué serviteur. ${ }^{11}$

La apelación explícita a la lectora femenina queda bien clara por la reiteración de Mes Dames, que supone un tratamiento afectivo en la misma línea de la expresión le beau sexe o Au beau sexe. Y es que, les guste o no, la mujer es la principal lectora de novelas. Esta última afirmación tampoco resulta gratuita, ya que responde al también generalizado tono machista que, en torno a este hecho, manifiestan muchos autores, y que también se encuentra en este prólogo: (...) où vous trouverez de quoi vous divertir, et de quoi vous instruire. Que cet mot, Mes Dames, ne vous fasse pas de peine.

Hechas estas observaciones, no voy a entrar en un análisis de la condición /consideración de la mujer lectora desde un enfoque sociológico, en el que inevitablemente se enfrentan las posturas misóginas con las denominadas feministas, aún sabiendo que en este siglo abundan las primeras pero tampoco escasean autores y autoras que proclaman y reivindican los méritos y reconocimiento de la mujer escritora-lectora. Sin embargo, respecto a la aparición de nuevas capas lectoras, considero más oportuno limitarme a destacar que el destinatario más importante de la novela francesa del XVIII, numéricamente hablando, es la mujer. Así lo demuestran las distintas denominaciones que en estos prólogos de novelas recibe el lector o público femenino. Por ejemplo, Rousseau declara en

${ }^{10}$ Anonyme: Valentine, recogido por Chr. Angelet in Recueil de Préfaces de romans du XVIIIe siècle, vol. II : 1751-1800. Publications de l'Université de Saint-Etienne/ Presses Universitaires de Louvain, 2003, pp. 306313 («Avertissement $»)$.

${ }^{11}$ Anonyme, Récréations morales et galantes, ou histoires véritables: avec des réflexions très utiles dédiées au beau sexe, 1717, in Nouvelles du XVIIIe siècle, ed. de H. Coulet, Gallimard, Coll. «Bibliothèque de la Pléiade», Paris, 2002, pp. 1273-1274. 
su prefacio a La Nouvelle Héloüse : Ce recueil avec son gothique ton convient mieux aux femmes que les livres de philosophie(..) Quant aux filles, c'est autre chose. Jamais fille chaste n'a lu de romans (...) Celle qui, malgré ce titre, en osera lire une seule page est une fille perdue $(. . .)^{12}$

Tal y como señala Rousseau existe la mujer y la jovencita. La primera es la lectora ideal de la novela, ya que además de entretenimiento siempre encuentra una utilidad, ya intelectual ya moral, por ser capaz de asimilar sus contenidos en el sentido que su autor se ha propuesto, mientras que la juventud, y mucho más las jovencitas, deben evitar su lectura ya que su inmadurez o falta de aprendizaje les impiden asimilar correctamente el contenido de las obras, y el pretendido ejemplo moral que se desprende del cuadro de costumbres escandaloso de muchas novelas, lejos de funcionar en la juventud como modelo a no imitar, es un modelo altamente corruptor.

Cuestión que debe controlar especialmente otro importante destinatario femenino de estas novelas: las madres. Veamos el prólogo con el que Rousseau introduce su Émile ou l'éducation (1762): Ce recueil de réflexions et d'observations, sans ordre et presque sans suite, fut commencé pour complaire à une bonne mère qui sait penser. Esta elección autorial del destinatario de la obra cobra todavía más fuerza cuando, en el segundo prólogo de la misma (incipit del libro I), insiste:

C'est à toi que je m'adresse, tendre et prévoyante mère, qui sus t'écarter de la grande route, et garantir l'arbrisseau naissant du choc des opinions humaines. Cultive, arrose la jeune plante avant qu'elle meure: ses fruits feront un jour tes délices. Forme de bonne heure une enceinte autour de l'âme de ton enfant; un autre en peut marquer le circuit, mais toi seule y dois poser la barrière. (...)..$^{13}$

Rousseau apela a esa madre cuyo papel es esencial en la educación del ser humano en los primeros años de la infancia, esto es: para que cultive y riegue la planta antes de que muera, dentro de la teoría o filosofía pedagógica que se propone poner en acción. Esta madre previsora debe proponerse prevenir antes que curar. Y, en el mismo sentido, se manifiesta Laclos en su Préface du rédacteur a Les liaisons dangereuses: ... l'utilité de l'Ouvrage (...) me paraît pourtant plus facile à établir. (...) que toute femme qui consent à recevoir dans sa société un homme sans mours, finit par en devenir la victime, l'autre, que toute mère est au moins imprudente, qui souffre qu'un autre qu'elle ait la confiance de sa fille. Para añadir, más adelante:

l'époque où celle-ci peut cesser d'être dangereuse et devenir utile, me paraît avoir été très bien saisie, pour son sexe, par une bonne mère, qui non seulement a de l'esprit, mais qui a du bon esprit. «Je croirais, me disait-elle, après avoir lu le manuscrit de cette correspondance, rendre un vrai service à ma fille, en lui donnant ce livre le jour de son mariage. "Si toutes les mères de famille en pensent ainsi, je me féliciterai éternellement de l'avoir publié. ${ }^{14}$

\footnotetext{
${ }^{12}$ Rousseau, Jean-Jacques, Julie ou la nouvelle Héloüse. Lettres de deux amants habitans d'une petite ville au pied des Alpes, 1761, Garnier- Flammarion, Paris, 1967, pp. 3-4 y 571-586.

${ }^{13}$ Rousseau, Jean-Jacques, Emile ou de l'éducation, 1762, Garnier-Flammarion, Paris, 1966, pp. 31-36.

${ }^{14}$ LaClos, Pierre-Abroise-François Choderlos de, Les liaisons dangereuses, 1782, in Laclos. Euvres Complètes, Gallimard, coll. «Bibliothèque de la Pléiade», Paris, 1979, pp. 7 y 8, respectivamente.
} 
Lo cierto es que las destinatarias de estas novelas son las madres y en última instancia las hijas, tuteladas por el buen criterio materno en cuanto al momento de administración de dicha lectura.

Otro autor que se propone educar a las jóvenes damiselas con los mismos argumentos pedagógicos, es Sade en La philosophie dans le boudoir, ou les instituteurs immoraux. Dialogues destinés à l'éducation des jeunes demoiselles (1795). Su prólogo ejemplifica la misma función de elección de un público, con idéntica intencionalidad de transmitir unos contenidos importantes por su utilidad pedagógica, en este caso inmoral. En el subtítulo de la obra, Sade parece destinarla a las jeunes demoiselles; sin embargo, en el título de su discurso prefacial abarca un público más amplio y ligeramente distinto: Aux libertins, cuya descripción siguiente nos enumera: Voluptueux de tous les âges et de tous les sexes, c'est à vous seuls que j'offre cet ouvrage; Femmes lubriques; Jeunes filles trop longtemps contenues dans les liens absurdes et dangereux d'une vertu fantastique et d'une religion dégoûtante; Et vous, aimables débauchés.

La intencionalidad, que Sade sin duda considera pedagógica a su manera, de transmitir una ideología o filosofía libertina, lógicamente va destinada al público libertino. Se trata de agradar a los que ya lo son y de convencer a los que todavía no lo son, pero son susceptibles de serlo, con lo que se construye un lector implícito con ciertas características y predisposiciones presentes en este enunciado. Entre el público que este discurso elige como destinatario se encuentran aquellos voluptuosos de cualquier edad y sexo, aquellas mujeres lúbricas y aquellos simpáticos degenerados. Realmente, para el conjunto que compone este lector implícito susceptible de convertirse en libertino, las cualidades no le faltan. Pero aparece otro bien distinto, les jeunes filles, cuyos únicos atributos calificativos y definitorios son el hecho de ser prisioneras tanto de una virtud fantástica (imposible) de fundamentos absurdos y peligrosos, como de una religión odiosa y fanática. El discurso sadiano de la acción actúa dirigido a todos los destinatarios del prólogo pero, en esta ocasión, interesa en especial su mención del público o receptor que más le interesa transformar con un objetivo liberador:

Jeunes filles trop longtemps contenues dans les liens absurdes et dangereux d'une vertu fantastique et d'une religion dégoûtante, imitez l'ardente Eugénie ; détruisez, foulez aux pieds, avec autant de rapidité qu'elle, tous les préceptes ridicules inculqués par d'imbéciles parents. ${ }^{15}$

Sade pretende una reacción por parte de este sector del público, de este lector implícito, y busca que reaccione y actúe en el sentido de la heroína sadiana. Efecto perlocutivo que transmite con la fuerza ilocutoria de los verbos imitez, détruisez, foulez. En este mismo sentido libertino se pronuncia el segundo prólogo de La Morlière a su obra Angola, Histoire indienne:

${ }^{15}$ SADE, Donatien-Alphonse-Françoise de, La philosophie dans le boudoir, ou les instituteurs immoraux, 1795, Una versión accesible se encuentra en la siguiente dirreción electrónica : http: //www. Sadeecrivain.com/philo/libert.htm. 
Aux petites maitresses.

C'est à vous que je dédie ce Livre, à vous qui êtes l'élixir précieux du beau sexe que j'adore, (...) Puissez vous après le plus tendre égarement, l'ouvrir pour y chercher de nouvelles leçons, et y répandre un souffle léger de cette volupté divine qui compose votre essence, $(\ldots)^{16}$

En esta misma dirección abundan los prólogos de novelas libertinas que dedican las obras al bello sexo, tal y como muestra el prólogo Au beau sexe que introduce la obra de Récréactions morales et galantes (...) avec de réflexions très utiles dédiées au beau sexe (1717). Y también los que comienzan con un explícito, Mes Dames, Mesdames, y terminan con el no menos explicito: J'ai l'honneur d'être, avec les plus brûlants désirs, De votre sexe complaisant et adorable. Hercule..$^{17}$

Distinto tono toman los prólogos escritos por mujeres novelistas que se dirigen a la mujer en una dirección de camaradería y reivindican su condición de mujer escritora. Como ejemplo representativo, está el Préface pour les dames, ou le portrait des femmes, que Olympe de Gouges añade a sus Mémoires de madame de Valmont, y que comienza así:

Mes très chères soeurs, c'est à vous à qui je recommande tous les défauts qui fourmillent dans mes productions. (...) Les hommes soutiennent que nous ne sommes propres exactement qu'à conduire un ménage; et que les femmes qui tendent à l'esprit, et se livrent avec prétention à la littérature, sont des êtres insupportables à société: $n$ 'y remplissant pas les utilités elles en deviennent l'ennui..$^{18}$

E idéntica complicidad femenina aparece en aquellos prólogos que, escritos por mujeres, presentan sus novelas como de gran interés para otras mujeres por compartir las mismas situaciones o experiencias, como expresa Mme de la Charrière en su prólogo a Lettres de Mistress Henley: Je crois que beaucoup de femmes sont dans le même cas que moi. ${ }^{19}$

Lo cierto es que la mujer no solo es la gran lectora de novelas, sino que también es quien más las demanda y, en este sentido, también abundan los prólogos que dejan claro que la obra que presentan ha sido escrita o publicada a petición de una dama. Cuestión a la que alude el prólogo de Voisenon a Le sultan Misapouf (1746), cuyo discurso preliminar comienza del modo siguiente: Vous m'avez non seulemnt demandé, madame, un conte de fées, vous avez même exigé qu'il fût fait (... ${ }^{20} \mathrm{Y}$ también el prólogo de Restif de la Bretonne a su obra Les Nuits de Paris ou le spectateur nocturne, en el que añade: Il a donné à cet ouvrage la forme animée du récit, parce qu'effectivement, il a rendu compte à une Femme de tout ce qu'il voyait. ${ }^{21}$ De manera que la mu-

\footnotetext{
${ }^{16}$ La Morlière, Jacques Rochette de, Angola, Histoire Indienne, 1746, Éd. Agra, Paris, 1746, pp. 3-18.

${ }^{17}$ Anonyme, Le petit-fils d'Hercule, 1748, in Romanciers libertins du XVIII ${ }^{e}$ siècle, ed. de Goulemot, Delon, Vázquez, et al., Gallimard, coll. «Bibliothèque de la Pléidade», Paris, 2005, pp. 1075-1080.

${ }^{18}$ Gouges, Olympe de, Mémoires de madame de Valmont, 1788, in Romans de Femmes du XVIIIe siècle, Éd. Robert Laffont, coll. «Bouquins», Paris, 1996, pp. 489-495.

${ }^{19}$ Charrière, Isabelle (Madame de), Lettres de Mistress Henley, 1784, in Ibid., pp. 353-354).

${ }^{20}$ Voisenon, Claude-Henri Fuzée, Abbé de, Le sultan Misapouf, 1746, in Romans libertins du XVIII ${ }^{e}$ siècle, Éd. Robert Laffont, coll. «Bouquins », Paris, 1993, pp. 499-501.

${ }^{21}$ Restif De La Bretonne, Nicolas-Edmund, Les Nuits de Paris ou le spectateur nocturne, 1788, in Éd. Firmin Didot, Paris, 1960, pp. 2-4.
} 
jer, como demandante y destinataria o lectora de novelas, invade nuestros prólogos y, tal y como puede verse, el corpus de prólogos de novelas del Siglo de las Luces que este análisis ${ }^{22}$ considera, no cesa de apelar de modo explícito a la Mujer en general y, más en concreto, a Damas, madres previsoras, compañeras y cómplices, también a mujeres lúbricas -sabias o rameras-, jovencitas, ya sean encantadoras e inocentes damiselas, chicas castas o chicas viciosas, y también a las amantes o a las que se aspira a que pronto aumenten el número de este colectivo. Y es que la mujer es la principal consumidora de novelas, algo que de modo irónico nos cuenta el prólogo en verso de Nerciat a Félicia ou mes fredaines:

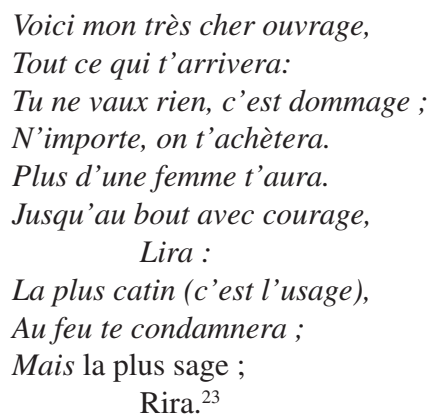

Realmente este autor sabe cuál será el futuro de su obra, sabe que el principal lector será la mujer, quien devora estas novelas, y no duda en apelar a su sabiduría e invitarla a que, en lugar de condenarlas de modo hipócrita, -como es costumbre-, se divierta y las disfrute.

Finalmente, otra cuestión que viene a confirmar el protagonismo de la mujer como principal lectora de la novela de esta época, es el hecho de que abundan las obras cuyos protagonistas son mujeres, independientemente de que los autores sean más numerosos que las autoras. Sin embargo, es preciso mencionar que muchos de los autores, cuando escriben sus obras, llevan a cabo un curioso ejercicio de travestimiento femenino. Es decir, adaptan su escritura al estilo femenino, en un esfuerzo por adoptar su expresión y psicología, y pensemos sobre todo en las numerosas memorias y lettres (romans épistolaires) que, en primera persona, nos hablan de personajes como Marianne, Valentine, la Religieuse (Suzanne Simonin), Julie, Justine, Margot la ravaudeuse, Thérèse philosophe, etc., en los cuales escuchamos a Thérèse, a Valentine, a la religieuse, o a Margot, desde el prólogo y durante toda la obra, o a Julie en las cartas que intercambia con su amante, o a Marianne en el relato de sus memorias, o a Justine en el relato de sus desgracias: todas estas obras están escritas por hombres, y ya no se trata de que la mujer sea la prota-

${ }^{22}$ El corpus de este análisis abarca 651 prólogos de 464 obras de 166 autores conocidos y 28 anónimos, representativos del panorama real de la narrativa de esta época, y corresponde al referido en mi Tesis Doctoral, Técnicas, modelos y análisis de la literatura prefacial de la novela francesa del siglo XVIII (UNED, 2010).

${ }^{23}$ Nerciat, Andréa de, Félicia ou mes fredaines, 1775, in Romanciers libertins du XVIII e siècle, ed. de Goulemot, Delon, Vázquez et al., Gallimard, coll. «Bibliothèque de la Pléiade», Paris, 2005, pp. 593-598. 
gonista principal de la obra, sino que es a ella misma a quien escuchamos, a menudo sin caer en la cuenta de que tras ello se esconde la pluma de un hombre. Aunque sabemos que este siglo gusta del disfraz y las falsas apariencias, en este caso la razón es otra: el novelista sabe que la sensibilidad femenina y el protagonista femenino son dos ingredientes fundamentales para el éxito del género novelesco.

Por otro lado, y debido a este mismo espíritu pedagógico y a la consiguiente función social que caracterizan a la escritura, así como a las nuevas condiciones materiales de la misma en este Siglo de las Luces, vemos cómo aparecen otros tipos de lectores, a comenzar por el público-lector, que nace por la importancia creciente de la opinión pública y por el concepto de clientela atribuido al lector-comprador e introducido por la comercialización del libro. Finalmente, también aparecerán otros dos nuevos modelos de lectores: el lector-peuple y el lector-citoyen. En estos casos, ese lector se modula en función de un concepto del hombre como proyecto social, como persona pública, y más adelante matizaré las diferencias entre ambos modelos. Y es cierto que uno de los grandes reproches que se le hace a la práctica de la lectura de este tiempo consiste en que, por tratarse de una acción íntima libro-lector, aleja a este último de otros intereses públicos y útiles para la sociedad entendida como colectivo; que aísla, en definitiva. Pero conforme avanza la segunda mitad del siglo, iremos encontrando a un lector explícito, plural y sociabilizado, al que responden las tres denominaciones de public, peuple y citoyen, lo cual viene a resolver el problema anterior. De este modo, Loaisel de Tréogate, por ejemplo, puede comenzar su prólogo a Dolbreuse del modo siguiente: Dans quelque genre que l'on écrive, on doit se proposer d'être utile. On doit avoir pour objet de contribuer, au moins en quelque chose, au bien public. ${ }^{24}$ Pues bien, estos lectores surgen por su adaptación a las nuevas concepciones de la escritura, que no sólo se encuentran en las reflexiones de los filósofos que las inspiran, sino que pronto se extienden y prenden de lleno en la mentalidad de la época.

Así es como estas apelaciones posibles del nuevo lector responden a una ideología marcada por el tránsito prerrevolucionario y -en función del matiz positivo que los apelativos de público, pueblo y ciudadano reciben- se deduce fácilmente que contienen también una importante carga propagandística. No en vano transmiten los autores más innovadores en el plano genérico su mensaje ideológico en función de la actualidad socio-política, de la demanda popular y en favor de un proyecto social, con una escritura comprometida que señala a un lector concreto al que se pretende guiar, educar y configurar. Anteriormente señalaba la importancia que el peso de la opinión pública ejerce sobre la escritura, y cómo ésta determina la aparición de un nuevo objetivo, le public - a partir de los elementos económicos que van a modificar el espacio lector, frente a destinatarios más concretos como el censeur o el critique, por no mencionar a los protectores aristócratas. Pues bien, lo cierto es que el censor como destinatario o lector no aparece explicitado, salvo en raras ocasiones, en las que curiosamente no se pide su favor o clemencia como al lector o al público, sino que se le critica o provoca, como en el caso del discurso prefacial de Mirabeau con el que introduce Le Rideau de levé ou l'éducation de Laure (1786):

${ }^{24}$ LoAisel de TrÉogate, Joseph-Marie, Dolbreuse, ou L'Homme du Siècle, 1783, Éd. Lettres Modernes, Coll. «Bibliothèque Introuvable», no 17, Paris, 1993, p. III.0 
Retirez-vous, censeurs atrabiliaires ;

Fuyez, dévots, hypocrites ou fous ;

Prudes, guenons, et vous, vieilles mégères:

Nos doux transports ne sont pas faits pour vous. ${ }^{25}$

El censor aparece de modo explícito para ser excluido como lector de la obra. Basta que se le impida disfrutar de los dulces transportes que la lectura de la misma promete, para que aumente el deseo de consumar dicha lectura. Pues bien, el análisis de estos prólogos demuestra que las menciones explícitas a los lectores censores o críticos son en la mayoría de los casos provocadoras. Otro prólogo que manifiesta este fenómeno es el Préface-approbation burlesque que Voltaire añade a Zadig (1747), donde la figura y rol del censor real recibe un tratamiento de burla y sátira, a causa de las incoherencias e irregularidades que presenta la actuación de estos miembros del aparato censor preventivo de esta época, por lo que, a modo de provocación, Voltaire parodia su actuación del modo siguiente:

Je soussigné, que me suis fait passer pour savant, et même pour homme d'esprit, ai lu ce manuscrit, que j'ai trouvé, malgré moi, curieux, amusant, moral, philosophique, digne de plaire à ceux mêmes qui haïssent les romans. Ainsi je l'ai décrié, et j'ai assuré monsieur le cadi-lesquier que c'est un ouvrage détestable. ${ }^{26}$

En cuanto al crítico-lector, también recibe un tratamiento de crítica, repulsa y provocación. Algo que también nos ofrece Voltaire en su incipit a La Princesse de Babylone (1768):

Et vous, maître Aliboron, dit Fréron, ci-devant soi-disant jésuite, vous dont le parnasse est tantôt à Bicêtre et tantôt au cabaret du coin; vous à qui l'on a rendu tant de justice sur tous les théâtres de l'Europe dans l'honnête comédie de L' Ecossaise; (...) Mon cher Aliboron, pour qui j'ai toujours eu tant de tendresse, et qui m'avez fait rire un mois de suite du temps de cette Écossaise, je vous recommande ma Princesse de Babylone; dites-en bien du mal afin qu'on la lise. Je ne vous oublierai point ici, gazetier ecclésiastique, illustre orateur des convulsionnaires, (...) ne manquez pas de dire dans vos feuilles, aussi pieuses qu'éloquentes et sensées, que la Princesse de Babylone est hérétique, déiste et athée. Tâchez surtout d'engager le sieur Riballier à faire condamner la Princesse de Babylone par la Sorbonne; vous ferez grand plaisir à mon libraire, à qui j'ai donné cette petite histoire pour ses étrennes. ${ }^{27}$

A pesar de las continuas disputas entre Voltaire y Fréron, se trata de un ejemplo bien representativo del tratamiento explícito del autor hacia el lector-crítico o censor. Sin embargo, y, paradójicamente, existe otro bien distinto cuando se trata del censor

${ }^{25}$ Mirabeau, Honoré-Gabriel de Riquetti, Le Rideau de levé ou l'éducation de Laure, 1786, Éd. Librairie Arthème Fayard, coll. «L'Enfer de la Bibliothèque Nationale», Paris, 1984, pp. 309-311.

${ }^{26}$ Voltaire, François Marie Arouët, Zadig ou la destinée, 1747, in Voltaire : Romans et Contes, Éd. Gallimard, coll. «Bibliothèque de la Pléiade», Paris, 1979, pp. 55-56.

${ }^{27}$ Voltaire, François Marie Arouët, La Princesse de Babylone, 1768, in Voltaire Romans et Contes, Éd. Gallimard, coll. «Bibliothèque de la Pléiade», Paris, 1979, pp. 413-414. 
implícito, el cual no es nombrado, pero es perfectamente deducible a partir de los abundantes prólogos preventivo-justificativos que la novela de este cronotopo desarrolla. Todos ellos sin duda responden a la gran vigilancia y represión que sobre la escritura ejerce la censura, y, muy especialmente, sobre la novela, al hecho de que hubo periodos en los que ésta fue literalmente prohibida y perseguida, en los que el novelista embastillado era una circunstancia tan siniestra como habitual. Por lo que todos aquellos prólogos preventivo-justificativos de estas novelas se dirigen, entre otros lectores, al censor implícito al que se pretende convencer de la inocencia de la novela ante las acusaciones que sufre en nombre de preceptos estéticos y éticos. Estos prólogos preventivo-justificativos se dirigen al censor implícito, ante el que se pretende hacer pasar las obras por lo que no son, con un estratégico discurso ambiguo y manipulador. Lo realmente significativo es que las apelaciones al censor o al crítico desaparecen de modo explícito en beneficio de las alusiones cada vez más importantes hacia el público, cuestión debida al mayor protagonismo que adquiere la opinión pública. Por lo cual, las alusiones y apelaciones al público proliferan de modo significativo frente a las tradicionales de lector. Veamos a quién se dirigen los siguientes prologuistas:

- M. Le Chevalier d'Yon: (...) et le présenter au public en douze parties. (...) Je n'ai qu'un mot à dire sur la bagatelle que je donne au public ${ }^{28}$

- Rétif de la Bretonne: J'offre avec confiance cet ouvrage au public (...) ${ }^{29}$

- Prévost : Il serait choquant de présenter au public un ouvrage de cette nature ( ... $)^{30}$

- Marivaux: Avant de donner cette histoire au public, il faut lui apprendre comment je l'ai trouvée. ${ }^{31}$

- Marmontel : Ce nouvel essai me réussit encore, et flatté d'avoir saisi le goût du public dans un genre que l'on daigna regarder comme nouveau, je continuai à m'y exercer. (...) J'aurais ménagé au public dans celle-ci (...) Ces encouragements ont produit un effet tout opposé à la négligence et j'espère que le public daignera s'en apercevoir. ${ }^{32}$

Resulta significativo que para muchos autores la diferencia entre el lector y el público radique en que el lector se define fundamentalmente por la acción de la lectura, mientras que el público además de ejercer la lectura, también realiza la acción de juzgar o generar una opinión. Veamos: Je n'entrerai dans aucun détail, le public jugera le motif et l'exécution ${ }^{33}$. En cualquier caso, muy a menudo se alude a esa opinión o recep-

${ }^{28}$ Yon, M. Le Chevalier d', Les femmes de mérite, histoires françaises, 1759, in Nouvelles du XVIII ${ }^{e}$ siècle, Éd. Gallimard, Ed. de H. Coulet, coll. «Bibliothèque de la Pléiade», Paris, 2002, pp. 581-582.

${ }^{29}$ Restif De La Bretonne, Nicolas-Edmund, La paysanne pervertie ou les dangers de la ville, 1784, Éd. Garnier-Flammarion, Paris, 1972. p. 37.

${ }^{30}$ Prévost. A.-F. Abbé de, Mémoires d'un honnête homme, 1745, in Euvres de Prévost, T. VI ${ }^{\mathrm{e}}$ Ed. Presses Universitaires de Grenoble, (ed. de Peter Tremewan), Grenoble, 1984, pp. 209-210.

${ }^{31}$ Marivaux, Pierre de Chamblain de, La vie de Marianne, 1731-42, in Marivaux, Romans, Éd. Gallimard, coll. «Bibliothèque de la Pléiade», Paris, 1949, p. 81.

${ }^{32}$ Marmontel, Jean -François, Contes Moraux, 1765, in Marmontel, Euvres complètes (17 vols., de los cuales los 3 primeros correspondes a los Contes), Éd. Née de la Rochelle, Paris, 1787, T. I, pp. II-VIII

${ }^{33}$ Dorat, Claude Joseph, Les malheurs de l'inconstance, 1772, in Romans libertins du XVIII ${ }^{e}$ siècle, Éd. Robert Laffont, coll. «Bouquins», ed. de Raymond Trousson, Paris, 1993, pp. 899-901. 
ción de la obra tras haberla leído, y así Marivaux nos aclara este importante matiz en su prólogo a L'Homère travesti: Je ne sais comment le public recevra l'Illiade travestie, dans l'opinion qu'on a que M. Scarron était inimitable dans ces sortes d'ouvrages ; (...) Si je voulais lecteur, je vous donnerais une comparaison (... $)^{34}$

Este mismo prólogo, en pocas líneas, alude al lector y al público con matices distintos ya que, mientras el lector se prevé leyendo este prólogo o dialogando con el prologuista, el público parece encontrarse en el futuro más o menos inmediato de su lectura, como una caja de resonancia de la opinión o acogida de la obra. Lo cierto es que esta opinión social, condiciona cada vez más la escritura de los autores y es lógico que el tradicional lector, de modo consciente o inconsciente, con frecuencia pase a denominarse público. Y aunque los autores se proponen escamotear la censura de sus obras, su principal objetivo es conquistar la opinión del público, aquél a quien se dirigen, quien demanda, lee y compra las obras, el único a quien le permiten juzgarlas.

Del mismo modo, cuando esta opinión social se traslade del campo literario al político y al ideológico, los destinatarios pasarán a denominarse peuple o citoyen. Y es que, ciertamente, tal y como reclamaba Beaumarchais, las obras deben ser juzgadas en último término por el público al que se destinan, un público que debe convertirse en sujeto accionador de las mismas, a partir de un concepto moderno de su lectura e interpretación que hoy puede parecernos convencional y generalmente admitido, pero que entonces no lo era tanto. Lo cual motivará que, en ocasiones, el juicio político o ideológico venga a sustituir o a imponerse al literario ya que -tal y como canta la última copla del Figaro-, las obras proyectan la vida del bon peuple que las entiende.

Restif de la Bretonne, en su Monsieur Nicolas (1796), indica en su prólogo autorial que su obra es de utilidad pública, frente a la tradicional mención de que la obra es útil para el lector, y este hecho se va a convertir, sin lugar a dudas, en la idea maestra del prólogo de este siglo. No en balde este autor descarta cualquier otra justificación ante el lector: Mais, en écrivant ce que j'ai fait, en rendant compte de ce que j'ai senti, en scrutant sévèrement mes motifs, en me disséquant moi-même pour ainsi dire, possible parviendrai-je, par cette anatomie douloureuse, à donner à ma nation le plus utile des livres, à éclairer mon siècle, à profiter à la postérité, (...) ${ }^{35}$

En este mismo sentido, Loaisel de Tréogate declara en su prefacio a Dolbreuse (1783): Dans quelque genre que l'on écrive, on doit se proposer d'être utile. On doit avoir pour objet de contribuer, au moins en quelque sorte, au bien public. ${ }^{36}$ Pues bien, en otras ocasiones, esa utilidad pública va a ir referida a un sector concreto que queda designado de modo implícito como destinatario de la obra; y un buen ejemplo lo constituye el lector implícito evocado en Les liaisons dangereuses: Lettres recueillies dans une

\footnotetext{
${ }^{34}$ Marivaux, Pierre Carlet de Chamblain de, L'Homère travesti,1716-17, in Marivaux, Euvres de jeunesse, Éd. Gallimard, Coll. «Bibliothèque de la Pléiade», ed. de Frédéric Deloffre, Paris, 1972, pp. 961975.

${ }^{35}$ Restif De La Bretonne, Nicolas-Edmund, Monsieur Nicolas, 1797, Éd. Gallimard, coll. «Bibliothèque de la Pléiade», Paris, 1989, p. 5.

${ }^{36}$ Loaisel de Tréogate, Joseph-Marie, Dolbreuse ou l'homme du siècle, ramené á la vérité par le sentiment et par la raison, 1783, Éd. Lettres Modernes, coll. «Bibliothèque Introuvable» Paris, 1993.
} 
société et publiées pour l'ínstruction de quelques autres ${ }^{37}$. Sabemos que la fórmula de estas cartas publicadas para equivale a obra escrita para, lo cual justifica también el realismo (la no-ficcionalidad) de las obras. También resulta evidente que el autor declara el objetivo pedagógico de su escritura, al tiempo que justifica su utilidad. Lo que no queda tan claro es quién es el destinatario de su obra, ya que cabe pensar que se trata de un lector implícito en el umbral de la obra pero perfectamente dibujado tras su lectura. Este subtítulo, que considero discurso prefacial, nos muestra cómo la actitud subversiva de Laclos no consiste únicamente y como la crítica ha insistido en presentar ante el espejo unas costumbres censurables, es decir, en la transmisión de un contenido moral de la obra que el prólogo ya se encargará de justificar como utilidad del mal ejemplo a evitar o combatir. La subversión de Laclos viene dada por la crítica de un sector de la sociedad, la aristocracia, y el partidismo por otro sector social concreto, la burguesía a la que se propone instruir, concienciar e impregnar de la ideología revolucionaria.

Así pues, nuestros prólogos prueban que, conforme nos acercamos a la Revolución del 89, las alusiones al lector se van politizando cada vez más. Restif de la Bretonne, en ese mismo año, denomina al lector, a su público, como peuple o Grand Tout, referencia representativa por sí misma del poder popular del momento. Además, el lecteur se ha convertido en citoyen, es decir, en depositario de unos derechos que el autor reconoce y respeta, y los lectores van a verse presentados como Nobles, Justes \& Honorables concitoyens. Así, en el prólogo dedicatoria a su Monsieur Nicolas apela al lector del modo siguiente: C'est donc un roman que je vous donne, honorable Lecteur (...) ${ }^{38}$

La simpatía del autor hacia la causa revolucionaria es evidente. Pues bien, parece que ese nuevo lector que comenzaba a fraguarse implícita y explícitamente en obras anteriores, tras todo el proceso instructivo al que ha sido sometido por los autores e ideólogos de la época, es ya un lector y un ser merecedor de todo tipo de elogios: noble, justo y honorable como hemos visto $\mathrm{y}$, ante todo y sobre todo, concitoyen, el más alto de los honores posible que, además, le convierte en partícipe de la empresa revolucionaria en marcha. Así es como Restif, en su préface a Les Nuits de Paris ou l'espectateur nocturne, declara: On vous présente avec confiance ces Tableaux Nocturnes, ô Concitoyens! comme les plus curieux (... $)^{39} \mathrm{Y}$ Mercier, por su parte, y en un tono más panfletario, en su Avant-propos a L'An Deux Mille Quatre Cent Quarante (1771), se dirige al lector del modo siguiente: Mes chers concitoyens! Vous ai-je vu gémir si fréquemment sur cette foule d'abus dont on est las de se plaindre $(\ldots)^{40} \mathrm{El}$ mismo autor declaraba en el prólogo de su Tableau de Paris (1781-89): J'ai fait des recherches dans toutes les classes de citoyens $(\ldots)^{41}$

Pues bien, Stromberg ${ }^{42}$ ha demostrado cómo gran parte de la mística de la Revolución quedó comprendida precisamente en el término citoyen hasta el punto de ser la

${ }^{37}$ Laclos, Euvres complètes, Paris, Gallimard, Col. «Bibliothèque de la Pléiade», 1979, p. 1.

${ }^{38}$ Restif De La Bretonne, Nicolas-Edmund, Monsieur Nicolas, Op. cit. p. XXXIX. (Dédicace).

${ }^{39}$ Restif De La Bretonne, Nicolas-Edmund, Les Nuits de Paris, 1788, Éd. Firmin Didot, Paris, 1960, pp. $2-4$.

${ }^{40}$ Mercier, Louis-SÉBAstien, L'An Deux Mille Quatre Cent Quarante 1771, Slatkine Reprints, Genève, 1979, pp. 1-40.

${ }^{41}$ Mercier, Louis-SÉBAstien, Tableau de Paris, 1781-89, Mercure de France, T. I., Paris, 1994, pp. 13-21.

${ }^{42}$ Stromberg, Roland N, Historia intelectual europea desde 1789, Debate, Madrid, 1991. 
clave para el nacimiento de una Nación: no como la proyección de una jerarquía de clases, sino como la articulación de una comunidad de ciudadanos que compartían equitativamente derechos y deberes. No olvidemos que, de acuerdo con la Declaración de los Derechos del Hombre y del Ciudadano -el gran manifiesto revolucionario- era el pueblo quien tenía, entre otros, el derecho a expresar libremente sus deseos en materia de gobierno y de cambiar de modelo de gobierno si el existente no respondía a sus expectativas.

Pero, para entender el auténtico significado de las nuevas apelaciones del lector, es preciso tener en cuenta a los filósofos que proporcionan esta terminología ideológica al discurso de la época. Para ello, es preciso recurrir de nuevo al Contrat social de Rousseau, que había de constituir un audaz proyecto de restauración de las libertades del individuo mediante la institución de las libertades garantizadas del ciudadano. Es bien sabido que la obra pretendía definir, y también precisar las condiciones de su aplicación, con un concepto fundamental: la ley, entendida como el principio de conciliación entre las aspiraciones individuales hacia la felicidad y las exigencias de la vida social. Pues bien, resulta oportuno recordar un fragmento del mismo que interesa especialmente al respecto:

À l'instant, au lieu de la personne particulière de chaque contractant, cet acte d'association produit un corps moral et collectif, composé d'autant de membres que l'assemblée a de voix, lequel reçoit de ce même acte son moi commun, sa vie et sa volonté. Cette personne publique, qui se forme ainsi par l'union de toutes autres, prenait autrefois le nom de Cité, et prend maintenant celui de République ou de corps politique, lequel est appelé par ses membres; État, quand il est passif; Souverain, quand il est actif; Puissance, en le comportant à ses semblables. À l'égard des associés, ils prennent collectivement le nom de Peuple, et s'appellent en particulier citoyens, comme participants à l'autorité souveraine, et Sujets, comme soumis aux lois de l'État. ${ }^{43}$

Este fragmento aclara mejor que cualquier otra referencia la diferencia entre el destinatario o lector peuple y el lector citoyen. Ambos se refieren a ese yo común, a esa persona pública de la que nos habla Rousseau, con la diferencia de que el primero es una denominación colectiva, mientras que el segundo tiene un carácter individual o particular. Lo realmente significativo de las nuevas designaciones del lector como public, peuple o citoyen es que, en cualquiera de los casos, se trata de un lector en $2^{\mathrm{a}}$ persona, ya del plural, ya del singular, pero siempre sociabilizado. En suma, todos ellos constituyen una persona pública, que conforma la unión de todos los individuos: se trata del yo sociabiliza$d o$ de la escritura que se dirige al tú sociabilizado de la lectura. Y entiendo que éste es el rasgo más relevante de la actitud intelectual, del espíritu filosófico de la época: el yo de la escritura y el tú de la lectura, que constituyen una reivindicación de libertad e individualismo, de un espíritu crítico que se enfrenta al conocimiento desde una óptica crítica propia. No obstante, tal y como demostrará la gran empresa colectiva de la Encyclopédie,

${ }^{43}$ Rousseau, J-J, Du Contrat social, (Livre I, chap. VI. «Du Pacte Social»), Paris, Garnier Flammarion, 1966 , p. 52. 
este yo individual también es susceptible de abdicar en favor de un proyecto social o colectivo, a diferencia del yo romántico posterior. Con todo ello, este individuo se difumina en un yo común o en una persona pública que, siendo el resultado de todas las individualidades, aporta la fórmula para conciliar las aspiraciones individuales de felicidad con las exigencias de la vida social. Individualismo y proyección social -esto es, búsqueda de verdades individuales para el bien social-, búsqueda de la felicidad aquí y ahora, racionalismo, espíritu crítico, etc., son los rasgos que definen el espíritu o la mentalidad del hombre ilustrado, del escritor y del destinatario de las obras en el siglo XVIII, y son también los factores que determinan la configuración del nuevo lector que, implícita y explícitamente -sobre todo a partir de la segunda mitad del siglo-, encontramos en las obras, y de modo privilegiado en nuestros prólogos. Ese nuevo lector explícito, peuple y citoyen, que los autores reclaman y pretenden configurar, ya había aparecido anteriormente de modo implícito y no estructurado bajo la forma de ciertos lecteurs más o menos sugestivos pero, con la nueva designación, vendrá a ser utilizado para provocar y difundir un discurso favorable a las ideas revolucionarias.

Pues bien, recordemos al respecto que dos de las grandes ideas de la Revolución radican en la soberanía popular y la igualdad de derechos. Por ello, debemos considerar que las configuraciones del nuevo lector como peuple y citoyen responden a la primera y segunda idea respectivamente, si bien ambas se complementan hasta el punto de que sin la energía de la primera -que determina al lector-peuple, más adelante al Grand Tout-, difícilmente podría llegarse hasta el lector-citoyen. Del mismo modo, para llegar a este destinatario peuple y citoyen también ha sido precisa esa energía del lector-public, que no solo alude al condicionamiento económico de la escritura y al nuevo concepto de clientela, sino que también apela a la libertad de expresión y a la progresiva soberanía del juicio del público, frente al implacable poder que detenta el tradicional aparato crítico, represivo y censor. La aparición de estos vocablos, la evolución de las distintas apelaciones del lector, muestran cómo esta transformación terminológica se corresponde paralelamente con las transformaciones sociales de la época. Pues bien, con ello no se trata -dentro de la recíproca relación texto/contexto- de privilegiar la influencia del primero sobre el segundo, o de reducir la literatura al mero aspecto político o social que, indudablemente, caracteriza a esta época, sino que me interesa mucho más establecer la aparición de este nuevo lector que constatamos como una configuración y una creación por parte de los autores, como una actitud del escritor que reacciona frente a las nuevas demandas y en función de la actualidad social.

Otros críticos se han mostrado más interesados por la otra perspectiva que cabe aplicar al fenómeno, y que ya ha sido referida. Es el caso, por ejemplo, de J. Kristeva ${ }^{44}$, para quien la Revolución no sólo se apoyaría sobre el audaz trabajo que autores como Voltaire, Diderot, Rousseau, Sade, entre otros, realizaron en los espacios del lenguaje y de la literatura; además de preconizar en sus leyes un cambio de vocabulario o de anunciarse en los discursos de sus actores, sino que, además, había de llevarse a cabo, literalmente, a través de la literatura. Y es que, según dicha autora, toda transformación social viene siempre acompañada por una transformación retórica. Está claro que nada nos impide es-

${ }^{44}$ Kristeva, Julia, Le langage cet inconnu, Paris, Ed. S.G.P.P., 1969. 
tar de acuerdo con su planteamiento, pero tampoco queremos ocultar que nuestro objetivo es distinto y pretendemos no derivar fuera de él. A título personal, me parece más interesante señalar que parece evidente que la transformación de la distinta apelación del lector por parte de los autores, de ciertos autores, y a partir de cierta época, resulta muy significativa y muestra las influencias del texto en el contexto y viceversa, de los autores en sus lectores y viceversa. No es por ello extraño que en este peculiar y tan complejo Siglo de las Luces, escritura y lectura se confundan, y que también las relaciones autor-lector se transformen. En último término, las nuevas designaciones del lector se estructuran en torno a un tu-peuple-citoyen socializado, en función del cual el nuevo lector-citoyen tiene unos derechos, y también unos deberes, hacia la lectura y hacia la comunidad de ciudadanos. Por ello, la nueva designación del lector como concitoyen vendrá a subrayar cómo el escritor y el lector son conscientes de tales derechos y deberes y cómo los comparten, y de qué manera, y con qué profundidad, escritura y lectura se habrán convertido en un acto de responsabilidad hacia la comunidad.

Pero quiero concluir con una reflexión literaria y destacando la función social e ideológica que tiene asignada la ficción en esta época, la cual condiciona una búsqueda y representación de la materia realista por parte de los autores, a través de distintas técnicas que persiguen un efecto realista, como pueda serlo la impregnación de las ficciones por la realidad. Es algo que se proponen las estrategias presentes en nuestros prólogos, a menudo a través del imperio de la primera persona, que es un modo verosímil de crear un efecto de autenticidad, o del relato del héroe doméstico. Pero este yo, aunque auténtico, resulta subjetivo y parcial, y su visión, su sentimiento y su voz pueden resultar engañosos. De manera que únicamente se consigue resolver los problemas ontológicos y epistemológicos del yo subjetivo mediante la multiplicidad de los puntos vista y de las voces, esto es, con la novela epistolar polifónica que, al igual que la estructura de la Encyclopédie, ofrece una visión plural y contrastada. Y, muy especialmente, mediante las miradas nuevas, que imponen lecturas $-\mathrm{y}$, por ello, escrituras- originales, que son las de esos lectores nuevos -mujeres, público, pueblo, citoyens, y concitoyens, especialmenteque los novelistas franceses del XVIII saben provocar y a los que, en sus prólogos, invocan de manera determinante. 
